\title{
Building expert consensus on problems of uncer- tainty and complexity in nanomaterial safety
}

\author{
Geoffrey Hunt ${ }^{\mathrm{a}}$ and Michael Riediker ${ }^{\mathrm{b}}$,*
}

a Centre for Bioethics \& Emerging Technologies, St Mary's University College, Waldegrave Road, TW1 4SX, UK

b Institut universitaire romand de Santé au Travail, Rue du Bugnon 21, CH-1011 Lausanne, Switzerland

A modified Delphi Method was used to determine the opinions of a range of experts from academia, industry and government in the field of nanotechnology, mainly those working in the areas of safety, occupational and environmental health, and nanotoxicology. The focus was on uncertainty and complexity. A questionnaire was prepared and the responses were collated and arranged by theme in a draft text. This text was then used in a second iteration for further comments both in a live plenary discussion at a nano-safety conference in Prague (November 2010) and subsequently electronically. A draft was prepared for final comments from a small panel before completion of the report. The participants identified the following ten priorities in the development of nano-safety: the need for realistic exposure scenarios, better established dose-response relationships, improved extrapolation from in vitro to in vivo, identification of the most relevant assessment parameters, understanding the dynamic biological interfaces, long term studies, information about stability and reactivity, understanding the behaviour of the protein corona, having test guidelines adapted to manufactured nanomaterials, and the development of more advanced statistical and computational methods. The discussions also investigated the basic nature of the uncertainties and how to distinguish between mere lack of data and intrinsic uncertainties that are a consequence of the complexity of living systems. The results of the consensual process are presented here, together with the identified priorities and some implications for strategy in nano-safety research and development.

Keywords: complexity, nanomaterial safety, scientific adequacy, uncertainty

* Corresponding author. Tel: +41 21314 7421; Fax: +41 21314 7430. E-mail: Michael.Riediker@hospvd.ch 


\section{Introduction}

A modified Delphi Method ${ }^{\mathbf{1}}$ was used to determine the opinions of a range of experts $(n=92)$ in the field of the safety of nanotechnology including manufactured nanomaterials (MNMs). The experts came mainly from the areas of safety, occupational and environmental health, and MNM toxicology. The focus was on issues of uncertainty and complexity in relation to data for risk assessment. "Uncertainty" was defined in terms of conceptual and theoretical parameters as well as insufficiency of data. "Complexity" was defined in terms partly taken from complexity theory, including "emergence". A questionnaire was prepared and the responses were collated and arranged by theme in a draft text. This text was then used in a second iteration for further comments both in a live plenary discussion at a nano-safety conference in Prague (November 2010) and subsequently electronically. A draft report was then prepared for a third stage of final comments from a panel of six experts (already involved in the prior stages) before publication.

The initial questionnaire covered questions on the scientific adequacy of current experimental and observational data in nanomaterial toxicology; the adequacy of methods (experimental protocols) for reaching definitive (scientifically adequate) conclusions; the kind of, and degree of, complexity in the toxicological basis of MNM behaviour that is or is not peculiar to the nanoscale and whether advanced (computational) methods are necessary; and the nature of the uncertainties involved in drawing scientific conclusions for biological and health impacts. By "adequate" is meant "from which at least some sound scientific explanations, predictions and control may be drawn".

In addition, at the end of the Prague meeting, participants were asked to identify and rank up to ten research priorities in the development of a MNMs risk assessment framework. These priorities were then discussed in plenary session, also in view of the growing importance of computational and stochastic methods. The results of the consensual process are presented here, together with the identified priorities and implications for strategy in nano-safety research and development.

\section{Priorities}

We first present the results of the concluding exercise. They take the form of a table of answers (Table 1) to a question that ended the discussion session:

What are currently the ten most critical requirements for the further development of a nanomaterials risk assessment framework?

Concerning manufactured MNMs, we need an understanding of the items presented in Table 1 . The list is randomly ordered, since participants did not agree on how to prioritize the items. After understanding these priorities, we can study the consolidated responses (by theme) to the questions from the first and second stages of the iterative process.

\footnotetext{
${ }^{1}$ Harold A. Linstone, Murray Turoff (eds) (2002). The Delphi Method: Techniques and Applications (http://is.njit.edu/pubs/delphibook/delphibook.pdf). Accessed 1 Sept 2010.
} 
Table 1. The ten most critical requirements for nano-safety.

\begin{tabular}{|l|l|}
\hline ITEM & DESCRIPTION \\
\hline $\begin{array}{l}\text { Realistic } \\
\text { exposure } \\
\text { scenarios }\end{array}$ & $\begin{array}{l}\text { This is critical, especially in relevant workplaces, with identification of high } \\
\text { risk exposure groups based on factors causing increased susceptibility to } \\
\text { exposure per se or to harm following exposure. }\end{array}$ \\
\hline $\begin{array}{l}\text { Dose-response } \\
\text { relationships }\end{array}$ & $\begin{array}{l}\text { This relationship must be established for different dose metrics; i.e. mass, } \\
\text { surface area, redox activity, etc. }\end{array}$ \\
\hline $\begin{array}{l}\text { From in vitro to } \\
\text { in vivo }\end{array}$ & $\begin{array}{l}\text { An understanding of the potential for, and limitations of extrapolation from in } \\
\text { vitro to } \text { in vivo is a critical requirement. }\end{array}$ \\
\hline $\begin{array}{l}\text { Assessment } \\
\text { parameters }\end{array}$ & $\begin{array}{l}\text { The parameters in the numerator and denominator for different exposure and hazard } \\
\text { assessment scenarios: per kg body weight or per m lung surface; and inclusion of } \\
\text { dose rate in data reporting to account for continuous (real world) exposures. }\end{array}$ \\
\hline $\begin{array}{l}\text { Dynamic } \\
\text { biological } \\
\text { interfaces }\end{array}$ & $\begin{array}{l}\text { Including subcellular interactions, in a dynamic/kinetic framework that allows } \\
\text { for evolution as living systems respond to the presence of MNMs; a model to } \\
\text { predict accumulation of MNMs in the body/organs. }\end{array}$ \\
\hline $\begin{array}{l}\text { Long-term } \\
\text { studies }\end{array}$ & $\begin{array}{l}\text { Consequences of lifetime exposure, aging profiles and biodegradation of MNMs } \\
\text { for exposure and hazard. }\end{array}$ \\
\hline $\begin{array}{l}\text { Stability and } \\
\text { reactivity }\end{array}$ & $\begin{array}{l}\text { Aggregation, agglomeration and stability of MNMs; reactivity and solubility in } \\
\text { various media; these would entail measurement procedures for the extent and } \\
\text { control of aggregation. }\end{array}$ \\
\hline Protein corona & $\begin{array}{l}\text { Behaviour and control of the "protein corona" phenomenon and biological } \\
\text { barrier transformations. }\end{array}$ \\
\hline $\begin{array}{l}\text { Nanomaterial } \\
\text { test guidelines }\end{array}$ & $\begin{array}{l}\text { How to adapt OECD Technical Guidelines for chemical testing, or demonstrate } \\
\text { in what respect the Guidelines do not fit the purpose of hazard screening for risk } \\
\text { assessment in the case of MNMs. }\end{array}$ \\
\hline $\begin{array}{l}\text { Advanced } \\
\text { methods }\end{array}$ & $\begin{array}{l}\text { The relevance of a systems biology approach, with advanced } \\
\text { statistical/computational methods for assessment of hazard and overall risks } \\
\text { from exposure to MNMs. }\end{array}$ \\
\hline
\end{tabular}

\section{Section 1 \\ SCIENTIFICALLY ADEQUATE DATA (experimental/observational facts)}

In the opinion of the experts, generally there are no "adequate" data (experimental and observational outcomes for risk assessment) at present, but in a few specific areas there is adequacy.

A significant number of experts are quite categorical that there are not yet data enabling scientifically adequate conclusions to be reached, even in some areas of nano-safety research. There is not yet much success in definitively establishing causal connexions between the nanomaterial, delivery parameters and biological and/or health impacts, especially in terms of separating nanospecific effects from those of ultrafine combustion particles. Perceived major areas of inadequacy of data are presented in Table 2.

Obviously, this list is not ordered into a conceptual hierarchy. Thus it may be noted that "dose-response" is a parameter built using data from a range of sources, exposure conditions or end points. Some experts think that there are a few areas with adequate data from which some preliminary conclusions regarding the safety of specific nanomaterials can be drawn. These are shown in Table 3. 
Table 2. Perceived main areas of data inadequacy.

\begin{tabular}{|l|l|}
\hline ITEM & DESCRIPTION \\
\hline Dose-response & $\begin{array}{l}\text { Dose in particle toxicology is a more difficult concept than dose of highly } \\
\text { soluble substances. Are we speaking only of the biologically available dose, and } \\
\text { of what kind of particle? }\end{array}$ \\
\hline $\begin{array}{l}\text { Temporal } \\
\text { analysis }\end{array}$ & $\begin{array}{l}\text { Data analysing the time course of a response, including the changes from } \\
\text { chronic exposure. }\end{array}$ \\
\hline Route & Adsorption, route and fate in animals, humans and the environment. \\
\hline In vitro/vivo & Integration of data from in vitro and in vivo studies. \\
\hline Kinetic data & Kinetic in vitro and in vivo data. \\
\hline Translation & Cross-species translation of findings. \\
\hline Inhalation & Inhalation exposure data (limited); aerosol nanosafety. \\
\hline Environment & Environmental exposure data; ecosystem impacts. \\
\hline $\begin{array}{l}\text { Most used } \\
\text { nanoscale } \\
\text { chemicals }\end{array}$ & $\begin{array}{l}\text { Data on TiO } \mathrm{O}_{2}, \mathrm{ZnO}, \mathrm{Ag}, \mathrm{Fe}, \mathrm{Fe} \text { oxides, Si and } \mathrm{SiO}_{2}, \text { fullerenes, carbon } \\
\text { nanotubes }(\mathrm{CNTs}), \mathrm{Cu} \text { and } \mathrm{CuO} \text { and Au data are accumulating, but are not yet } \\
\text { scientifically adequate, and often contradictory, as a result of issues such as } \\
\text { poor understanding of the available dose of particles. }\end{array}$ \\
\hline
\end{tabular}

Table 3. Perceived progress made on data (by end 2010).

\begin{tabular}{|l|l|}
\hline ITEM & DESCRIPTION \\
\hline $\begin{array}{l}\text { Some physical } \\
\text { characterization }\end{array}$ & $\begin{array}{l}\text { Some physical characterization for certain MNMs, such as shape, chemical } \\
\text { reactivity and stability data. However, doubt is thrown on the utility of a } \\
\text { "full characterization" approach, since MNMs present differently to } \\
\text { biological systems. Examples given are: "in different OECD test media some } \\
\text { MNMs are different in terms of zeta potential, size distribution, etc."; "The } \\
\text { effects of natural organic materials (NOM) and other biomolecules, etc. on } \\
\text { zeta potential, size, size distribution, etc.". }\end{array}$ \\
\hline SARs for CNTs & $\begin{array}{l}\text { CNTs show an emerging pattern of structure-activity relationships (SARs); } \\
\text { e.g., long CNTs are more pathogenic than short CNTs. }\end{array}$ \\
\hline Some workplaces & $\begin{array}{l}\text { Data obtained from selected working environments; e.g., pilot studies in } \\
\text { ambient air of the workplace. }\end{array}$ \\
\hline Filters & $\begin{array}{l}\text { Fibre filter efficiency has proven to be even better for nanoscale particles } \\
\text { than microscale particles; respiratory filters are efficient collectors of } \\
\text { nanoparticles; the maximum penetrating particle size (MPPS) for } \\
\text { electrostatic filters. }\end{array}$ \\
\hline
\end{tabular}

Even though nanotoxicological conclusions are sparse, at least the importance of characterization data on size, shape, surface charge, etc. under the appropriate test or exposure conditions has begun to be understood by those in the field. One consideration is that experts do not always know what data others may have, due to poor communication or the confidential nature of business information, and therefore cannot make a full judgment on adequacy here.

Participants were also asked whether they consider adequate data are imminent in any areas. It was pointed out that internationally there are number of programmes and projects running on the interaction between MNMs and biological systems, including fate and effect. One respondent suggested that "within three years we may have significant new information in this field". There are three areas in which scientifically adequate nanomaterial toxicology data 
are perceived to be imminent (by 2015, approximately): exposure assessment and exposure control (closed systems, exhaust systems); analytical determination methods allowing more and better physicochemical characterization of MNMs; and comprehensive risk evaluation for a few MNMs, in particular $\mathrm{TiO}_{2}, \mathrm{Ag}$ and CNTs. However, concerning the last of these, we are reminded that they "are not a uniform class of materials and the properties of CNTs may differ depending on route of synthesis, content of other residual contaminants, and so forth".

Most of the inadequately established parameters listed above are regarded as "urgent" by the experts. Those specifically mentioned as urgent are presented in Table 4.

Table 4. Most urgent data needed.

\begin{tabular}{|l|l|}
\hline Human-relevant & $\begin{array}{l}\text { Data directly relevant to humans, especially for at-risk or vulnerable populations, } \\
\text { such as foetuses, the elderly and those with chronic inflammatory conditions. }\end{array}$ \\
\hline Data for OEL & $\begin{array}{l}\text { Data for setting occupational exposure limits (OEL) can only be fixed after effects } \\
\text { are known from model studies or from human incident cases, provided the } \\
\text { causality has been confirmed. }\end{array}$ \\
\hline $\begin{array}{l}\text { Biomarkers for } \\
\text { monitoring }\end{array}$ & $\begin{array}{l}\text { Appropriate biomarkers to monitor exposed individuals, although again, } \\
\text { distinguishing pathologic effects from MNMs versus ultrafine pollution } \\
\text { particulates may be difficult or even impossible, }\end{array}$ \\
\hline $\begin{array}{l}\text { Aerosol hazard } \\
\text { parameters }\end{array}$ & $\begin{array}{l}\text { Understanding what are the most relevant hazard parameters of aerosol } \\
\text { nanoparticles, such as mass, number, surface area, concentration, reactivity, etc.); } \\
\text { but by what method? }\end{array}$ \\
\hline $\begin{array}{l}\text { Data about } \\
\text { photocatalysts }\end{array}$ & $\begin{array}{l}\text { The environmental fate of photocatalytic substances (e.g., titanium oxide and zinc } \\
\text { oxide) and silver when they wash out from applications. }\end{array}$ \\
\hline $\begin{array}{l}\text { Fibre pathology } \\
\text { mechanisms }\end{array}$ & $\begin{array}{l}\text { Data enabling a theoretical/causal understanding of the pathological impacts of } \\
\text { CNTs and other fibres. }\end{array}$ \\
\hline $\begin{array}{l}\text { Fate of nano- } \\
\text { carbon }\end{array}$ & $\begin{array}{l}\text { Fate of carbon nanomaterials, such as fullerenes, CNTs and particles after disposal } \\
\text { of these materials and products containing them. }\end{array}$ \\
\hline Life cycle data & Data to build life cycles of specific MNMs. \\
\hline Ecotoxicity & Data on nanoparticle toxicity to ecosystems in soil and water. \\
\hline $\begin{array}{l}\text { Predictive } \\
\text { models }\end{array}$ & $\begin{array}{l}\text { Sufficient body of good quality data for mechanistic understanding of the impacts } \\
\text { of different MNMs; towards a classification of MNMs based on their biological } \\
\text { behaviour/impacts, possibly via study of the biomolecular corona; and developing } \\
\text { a set of human and environmental predictive models for toxicological effects. }\end{array}$ \\
\hline Consumer data & $\begin{array}{l}\text { Data about where nanomaterials are most massively or sensitively used, including } \\
\text { food, food packaging, cosmetics and health products. }\end{array}$ \\
\hline
\end{tabular}

The authors note how many of these ideas imply that MNM toxicology urgently needs to reach a point where the quantity and quality of data enable theoretical and predictive understanding. A concomitant theme that emerges from the survey is that high-throughput methods and advanced computational tools may be necessary to facilitate and accelerate this enabling process.

\section{Section 2}

SCIENTIFICALLY ADEQUATE METHODS (protocols, tests, instruments)

A large proportion of respondents thought that definitions, standardization and reference materials were needed for the development of adequate methods. Those who were familiar with 
CEN/ISO publications thought these definitions were often in need of refining and greater applicability. Even an "agreed, clear and useful definition of MNMs" was still required. ${ }^{2}$ One respondent asked whether one nanoparticle in a swimming pool counts as a "nanosuspension". There is a lack of standardized methods and (quantitative as well as qualitative) comparability criteria for nearly every characterization parameter, such as solubility, agglomeration and kinetics, and even a lack of reliably labelled materials. Another lack is reference materials for benchmarking and, more fundamentally, a concept of what constitutes a reliable reference material beyond size and composition. Urgent needs should include positive and negative controls for specific biological end points.

Respondents generally thought that although there are methods currently in use in some areas, they are validated for use with bulk chemicals rather than MNMs. Additionally, current methods are mostly limited, unreliable and unrelated, making for difficulties in the interpretation, translatability, comparability and unification of findings. As one respondent put it: "Standardized protocols are being developed, but are still not widely available." The general suggestion seems to be that new methods, more appropriate to the particle/bio interface at the nanoscale, need to be devised in a standardized fashion with adequate reference materials. The absence of basic nanometrological data was perceived as a major stumbling block.

At present, causal relationships between a well defined set of MNMs and well defined particular effects (especially over time) are difficult, if not impossible, to establish. One respondent avers that "A well defined set of test MNMs should have one parameter systematically varied, keeping all others constant; for example, change size or change surface charge or change shape or change composition or change crystal structure, and so forth." We should not work with "whatever materials happen to be available. This is also a major challenge. Current testing programmes use a single batch of each different MNM, but this is scientifically misguided in terms of assessing overall safety of nanomaterials, as the data might be representative only of that specific batch".

Some think that there are some adequate general methods in the fields of immunotoxicology, genotoxicology and morphological analyses, for example, as well as "toxicology physicochemical characterization". Inhalation study protocols that are derived from micrometre-sized particle suspension processing studies may also be useful. However, "standardization of tests is a challenge, as there are always small variations within laboratories. It is very important to consider dispersion quality and evolution in the test media during in vitro exposures. Is it possible to "clean" your cells after exposure to nanoparticles in order to ensure that nanoparticles stuck at the membrane are not counted as internalized? Washing and centrifuging sends particles to the bottom in a cell pellet; new methods need to be developed for washing cells to ensure quantitative reproducibility".

Specifically mentioned are: "methods determining size and concentration of aerosol particles that enter the human respiratory tract; both mass and number size distributions of particles to be measured using physically sound and reproducible methods in the relevant size range". Methods for "determining the deposition of particles in the respiratory tract are more or less well elaborated". For determining the new properties of nanomaterials, application of some

${ }^{2}$ ISO/TC 229, Nanotechnologies. www.iso.org/iso/pressrelease.htm?refid=Ref980 
existing analytical methods might be adapted, for example, to very low concentrations for investigating dynamics, fate and degradation of materials.

Affordable, intelligent toxicity testing and user-friendly on-line measurement instruments seem to be imminent. However, a sceptic opined that prior to their introduction, "more projects are needed on the influences of the methodological aspects underpinning poor measurements" and this requires harmonized studies. "Poor measurements may be related to aspects of cell culture, cell type, type and choice of assay, exposure media and dosimetry."

\section{Absent or inadequate methods}

The absent or inadequate methods specifically mentioned by participants are presented in Table 5 .

Table 5. Absent or inadequate methods.

\begin{tabular}{|c|c|}
\hline $\begin{array}{l}\text { Specific nano-EHS } \\
\text { methods }\end{array}$ & $\begin{array}{l}\text { Methods for specific information relevant to environment, health and } \\
\text { safety (EHS); new exposure-monitoring instruments. }\end{array}$ \\
\hline $\begin{array}{l}\text { Translatable } \\
\text { methods }\end{array}$ & In vitro test methods that have predictive power for in vivo studies. \\
\hline $\begin{array}{l}\text { Advanced methods } \\
\text { with prediction- } \\
\text { building power }\end{array}$ & $\begin{array}{l}\text { Methods that can help build a theoretical and predictive understanding of } \\
\text { the nano/bio interface, MNMs' physicochemical properties and the nature } \\
\text { of the corona formed, and from the nature of the corona to the likely } \\
\text { biological fate and behaviour. }\end{array}$ \\
\hline Reliable methods & $\begin{array}{l}\text { Systematic testing of interference of MNMs with test methods' readout } \\
\text { systems, etc., in order to be sure of data values. Simple checks should be } \\
\text { included in all protocols and required by editors prior to publication of } \\
\text { data. }\end{array}$ \\
\hline $\begin{array}{l}\text { Standardized assay } \\
\text { protocols }\end{array}$ & Standard protocols for MNM preparations in biological assay media. \\
\hline Better dosimetry & Development of in vitro dosimetry. \\
\hline Kinetic methods & $\begin{array}{l}\text { Methods that enhance uptake/translocation/distribution studies; modelling } \\
\text { procedures for kinetic behaviour; comparison of MNM behaviour with } \\
\text { their micrometre-sized counterparts. }\end{array}$ \\
\hline $\begin{array}{l}\text { Purity, stability, } \\
\text { batch invariance }\end{array}$ & $\begin{array}{l}\text { Methods that help scientists with the purity of samples, batch-to-batch } \\
\text { variability and stability of a sample over time (good standardized methods } \\
\text { are available for purity analysis of soluble chemicals (i.e., elemental } \\
\text { analysis) and some may be also suitable for MNMs). }\end{array}$ \\
\hline Validated methods & $\begin{array}{l}\text { Validated and standardized test methods, for in vitro and in vivo testing } \\
\text { that are translatable, and are practically and routinely implementable by } \\
\text { researchers. }\end{array}$ \\
\hline High throughput & Methods for high-throughput preliminary/basic testing of nanomaterials. \\
\hline Temporal methods & $\begin{array}{l}\text { Time-related studies (including long term); at least, exploring the design } \\
\text { of such. }\end{array}$ \\
\hline
\end{tabular}

\section{Imminent and urgent methods}

A number of experts thought there were no areas in which an adequate method is imminent. However, candidates mentioned were: some exposure assessment methods; some material characterization relevant to toxicity; analytical detection in biological matrices for some 
specific MNMs, such as metals; and "standardized methods for the generation of MNMs with specific characteristics, although significant work is still required to understand the biological consequences of the batch-to-batch variability of MNMs". On a practical workplace level, the following were mentioned as imminent: engineering control techniques such as source enclosure, local exhaust ventilation systems and filter efficiency; testing of personal (occupational) protection devices. The most urgent areas for the creation or improvement of methods are identified in Table 6 .

Table 6. Methods most urgently in need of development.

\begin{tabular}{|c|c|}
\hline $\begin{array}{l}\text { Exposure assessment } \\
\text { methods }\end{array}$ & $\begin{array}{l}\text { Exposure assessment methods, especially regarding background } \\
\text { distinction between MNMs and ubiquitous ultrafine particles. Better } \\
\text { methods for determining exposure to CNT; "proposed OELs are very } \\
\text { low" (NIOSH) }\end{array}$ \\
\hline $\begin{array}{l}\text { Prediction-building } \\
\text { methods }\end{array}$ & $\begin{array}{l}\text { Surrogate measures for prediction of nanoparticle transport, persistence, } \\
\text { bioaccumulation and toxicity. }\end{array}$ \\
\hline Dosimetry & $\begin{array}{l}\text { In vitro assessment, validity and round robin testing", dosimetry and } \\
\text { relationship to in vivo exposure and dosimetry; this should cover } \\
\text { exposure dose, medium dose, delivered dose, intracellular dose, } \\
\text { subcellular dose, as well as organism dose, tissue dose, etc. }\end{array}$ \\
\hline Monitoring humans & $\begin{array}{l}\text { Methods for continuous/cumulative examination of humans' } \\
\text { occupational and environmental exposures. Biomarkers specific to } \\
\text { MNMs exposure. }\end{array}$ \\
\hline $\begin{array}{l}\text { Specific methods for } \\
\text { fullerenes and } \mathrm{Ag}\end{array}$ & $\begin{array}{l}\text { Specifically for fullerenes and silver, since they are now mass-produced; } \\
\text { test methods for human and ecological impacts. }\end{array}$ \\
\hline Chemical analysis & $\begin{array}{l}\text { Determination of chemical composition of MNMs, especially towards } \\
\text { lowering their detection limits and coping with variability and impurities. } \\
\text { Also, the determination of nanoparticles in complex materials-does this } \\
\text { mean that more sensitive methods are needed? }\end{array}$ \\
\hline Nanometrology & Methods based on traceable nanometrological information. \\
\hline $\begin{array}{l}\text { General detection } \\
\text { method }\end{array}$ & $\begin{array}{l}\text { A general method to screen any material for nanoparticulate content, } \\
\text { which would give a size/number profile of the substance, and maybe } \\
\text { more physicochemical data. }\end{array}$ \\
\hline $\begin{array}{l}\text { Characterization } \\
\text { standard }\end{array}$ & $\begin{array}{l}\text { Standard determination of the fundamental nano-relevant properties to } \\
\text { be tested in all cases (starting at a nanosized fraction of, e.g., } 0.1 \% \mathrm{w} / \mathrm{W} \\
\text { of a substance, mixture or product). }\end{array}$ \\
\hline Method innovation & $\begin{array}{l}\text { Application and refinement for MNM risk assessment of such methods } \\
\text { as weight of evidence (WoE), multicriteria diversity analysis (MCDA) } \\
\text { and Bayesian methods. Long-term EHS methods. }\end{array}$ \\
\hline
\end{tabular}

${ }^{\dagger}$ National Institute for Occupational Safety and Health, USA.

${ }^{\ddagger}$ Interlaboratory testing in which a given sample is tested by different labs, often using different methods to assess the statistical agreement of the results obtained.

Regarding the call for a general detection method, another participant observed: "This would be excellent, but is quite ambitious. It would have to combine several methods, for example chemical analysis with visualization/size analysis and possibly also BET measurements (analysis technique for the measurement of the specific surface area of a material), such as along the lines of the SCENHIR nanodefinitions. A number of possible 
methods are available that will allow the separation of tissues and nanoparticles. Consider the disc centrifuge, which is destructive, or field flow fractionation, which is nondestructive; and coupled to detection with ICP-MS or UV absorption." A significant challenge here is that due to the enormous variability of composition of MNMs, many techniques are only suited to detection of a subset of MNMs.

One participant called for "an update of existing guidance on test methods, so that they can be used for nanomaterials as well". One reply to this was: "This is key. Even a statement that they have not yet been validated for MNMs would be a start!"

\section{Section 3}

\section{COMPLEXITY IN NANOMATERIAL TOXICOLOGY}

(Surface area reactivity, cellular penetration, emergent properties, stochastic approaches)

While a few respondents think there is no special or peculiar complexity in the toxicological basis of nanoscale particle behaviour, the majority think there is. As one might expect, the reasons given vary considerably. Among the minority was the comment: "No, there is no difference because all chemicals depend on surface area for biological reaction, some greater and some lesser, but there is nothing unique." A reaction to that particular response was that, "nanoparticles interact with biomolecules and assume a biological identity of their own via which they actively engage with biological machinery".

One cogent comment was: "Living organisms are complex, nonlinear, adaptive and dynamic systems, and 'traditional' scientific methods (standard tests, reference materials, etc.) may completely miss something of importance. Nonstandardized tests may very well turn out to be an experimental Monte Carlo characterization of the real thing once enough data are available."

One general reason suggested for the complexity of MNM behaviour is their mobility in relation to cells and tissue barriers: "The penetration mechanism through cellular membranes appears to depend crucially on the nanoscale size (very different from that of micrometre-sized particles) rather than the chemical substance, the shape and the surface characteristics. The chemical substance and surface characteristics are important for the effects of nanoparticles in the cells. This needs to be fully investigated."

A general reason given for the complexity of characterizing MNMs was that "the properties of these particles can change in contact with other materials, so in theory it would be necessary to study every MNM in contact with every material that in real life it could be in contact with". Indeed, this is codified to an extent in the REACH guidelines, which requires a manufacturer or importer to specify and assess end uses of the materials and to ensure their suitability/safety for those uses. Specific reasons given for assuming that there is a special degree and/or kind of complexity for toxicologists to cope with at the nanoscale are shown in Table 7.

One respondent warned of the tendency "to generalize results obtained for some MNMs to all in that category (e.g., CNTs) or, worse, to the whole area of MNMs. A number of experts agree that the examples given in the questionnaire are of particular concern, namely: surfacearea reactivity; the extent of disruptive molecular recognition; degree of interactivity; and synergistic effects. Of course, there appeared to be different assumptions about the meaning of 
Table 7. Special complexity of MNMs?

\begin{tabular}{|c|c|}
\hline $\begin{array}{l}\text { Cellular } \\
\text { penetrability and } \\
\text { kinetics }\end{array}$ & $\begin{array}{l}\text { High penetrability of cells, cell structures and barriers in a manner difficult } \\
\text { to control. The size, shape, surface, charge etc. determine behaviour, } \\
\text { which actively engages endogenous biological/cellular machinery. Thus } \\
\text { variability in clearance/uptake, cellular kinetics, dose-response and } \\
\text { mechanism of penetration result, depending on the route of exposure. }\end{array}$ \\
\hline $\begin{array}{l}\text { Surface area and } \\
\text { properties }\end{array}$ & $\begin{array}{l}\text { Surface-area reactivity; the local impacts of nanoscale surface properties; } \\
\text { e.g., "Changes in reactivity on surfaces that occur as the fraction of atoms } \\
\text { on the surface of a separate phase become the majority are not well } \\
\text { understood." }\end{array}$ \\
\hline Interactivity & $\begin{array}{l}\text { Poorly understood interactions of MNMs with each other and with } \\
\text { surrounding molecules, such as proteins, lipids, carbohydrates and } \\
\text { surfactants. }\end{array}$ \\
\hline Bioavailability & $\begin{array}{l}\text { Little understood bioavailability of nano-objects, which may depend on a } \\
\text { number of nanoscale characteristics. }\end{array}$ \\
\hline $\begin{array}{l}\text { Instability, } \\
\text { variability }\end{array}$ & $\begin{array}{l}\text { Apparently identical nano-objects can vary in their chemical and physical } \\
\text { makeup; they can change over time and in different environments; e.g., } \\
\text { within the body. }\end{array}$ \\
\hline $\begin{array}{l}\text { Are chemistry- } \\
\text { based models } \\
\text { limited? }\end{array}$ & $\begin{array}{l}\text { At the nanoscale it is physics that counts, but traditional toxicology } \\
\text { derives from mainstream chemistry. One respondent asked: "Does this } \\
\text { mean that traditional risk assessment methods don't apply?" Another } \\
\text { contrasted the chemistry of insoluble/particulate matter and the chemistry } \\
\text { of solutions, with different behaviours. }\end{array}$ \\
\hline Size, but wl & $\begin{array}{l}\text { The }<100 \mathrm{~nm} \text { definition is unhelpful regarding the size at which specific } \\
\text { properties of MNMs arise. At even smaller sizes }(<20 \mathrm{~nm}) \text { quantum } \\
\text { effects may arise, which may yield unexpected biological/toxicological } \\
\text { effects that are difficult to predict. Few examples of "true" nanospecific } \\
\text { toxicological effects have been presented. Another respondent pointed out: } \\
\text { "For the interaction with cells, particles }>100 \mathrm{~nm} \text { (i.e., 200-300 nm) } \\
\text { behave like "nanoparticles'; e.g., a } 200 \mathrm{~nm} \text { polystyrene particle can } \\
\text { penetrate a red blood cell." }\end{array}$ \\
\hline $\begin{array}{l}\text { Coating is } \\
\text { recognized }\end{array}$ & $\begin{array}{l}\text { What cells/organs/organisms sense and interact with the coated } \\
\text { nanoparticle, which resembles a biological entity? From a toxicological } \\
\text { viewpoint the impact parameters for MNMs relate to the "biological } \\
\text { identity" and biological availability (i.e., MNMs' increased access to } \\
\text { subcellular locations relative to "bulk" chemicals). }\end{array}$ \\
\hline $\begin{array}{l}\text { Properties are } \\
\text { scale-dependent }\end{array}$ & $\begin{array}{l}\text { The properties of MNMs are not easily predictable from those of the } \\
\text { component parts (in an ascending scale), or from those of matter at the } \\
\text { macroscopic scale (in a descending scale). }\end{array}$ \\
\hline $\begin{array}{l}\text { Properties are } \\
\text { age-dependent }\end{array}$ & $\begin{array}{l}\text { The situation is always complicated by the aging of the MNMs, which can } \\
\text { reduce the toxicity, as well as effects from contaminants (e.g., metals). }\end{array}$ \\
\hline $\begin{array}{l}\text { Special properties } \\
\text { of concern }\end{array}$ & $\begin{array}{l}\text { Special properties such as photochemical and catalytic activity are complex } \\
\text { and of concern when MNMs go outside their supposed area of application. }\end{array}$ \\
\hline
\end{tabular}

"complexity". One said that "complexity only arises when dealing with partially understood systems like ecosystems, climate and response of living things to mixtures of environmental pollutants". Another remarked that truly complex environments or physiological systems have been observed that lead to results which may be "entirely contrary to laboratory experiments". 
Other specific factors mentioned as being of special concern, besides those mentioned above, are the recognition or nonrecognition of nanoscale objects by the immune system, oxidative stress mechanisms, proinflammatory effect mechanisms, the time-variable aspects of temperature and light exposure, and the biopersistence, bioaccumulation, hydrophilicity, charge and polarity of MNMs - all raising issues of complexity, risk assessment and manageability. In short, as one respondent put it: "There is an enormous number of parameters that are dependent on each other."

It was pointed out that there is evidence from very recent findings that the immune system does react to nanoparticles, and that nanoparticles have an immunomodulatory effect. ${ }^{3}$

The role of the "corona" of biomolecules (proteins, lipids, sugars) on the surface of nanoparticles was also raised. Is the corona dynamic and how does it affect how cells sense nanoparticles? One expert remarked, "This is certainly one of the most important points for the interaction of nanoparticles with biological systems. It may determine substantially the fate and the effects of nanoparticles in cells and tissues. ${ }^{, 4,5,6}$ One particularly interesting remark was: "An important emerging trend is that of impacts from MNMs in organelles/cells without direct contact. Some researchers showed genotoxicity across a transwell filter membrane without the nanoparticles passing through the membrane. This introduces a whole new level of complexity related to nanoparticle-induced signalling, which can be from surface-adhered MNMs or from nanoparticles taken up into cells and passed into other cell types, etc."

\section{Computational and statistical approaches?}

In view of the admitted complexity and unpredictability of MNM behaviour, including from a toxicological point of view, the experts were asked to consider any special merits of a stochastic and computational approach., ${ }^{\mathbf{8}, 10}$ One response was, "I don't think so, since the major problems are still at the level of how to handle the nanomaterials in the experiments."

3 Gertie J. Oostingh, Eudald Casals, Paola Italiani et al. Problems and challenges in the development and validation of human cell-based assays to determine nanoparticle-induced immunomodulatory effects, Particle and Fibre Toxicology, 8:8 (2011) http://www.particleandfibretoxicology. com/content/8/1/8

${ }^{4}$ Lesniak, A., Campbell, A., Monopoli, M.P. Serum heat inactivation affects protein corona composition and nanoparticle uptake. Biomaterials 31 (2010) 9511-9518.

5 Tommy Cedervall, Iseult Lynch, Stina Lindman, et al. Understanding the nanoparticle-protein corona using methods to quantify exchange rates and affinities of proteins for nanoparticles. Proceedings of the National Academy of Sciences of the USA 104 (2007) 2050-2055.

6 Thomas Alured Faunce, John White, Klaus I. Matthaei. Integrated research into the nanoparticleprotein corona: a new focus for safe, sustainable and equitable development of nanomedicines. Nanomedicine 3 (2008) 859-866

7 Gevdeep Bhabra, Aman Sood, Brenton Fisher et al. Nanoparticles can cause DNA damage across a cellular barrier. Nature Nanotechnology 4 (2009) 876-883.

8 John M. Balbus. Ushering in the new toxicology: toxicogenomics and the public interest. Environmental Health Perspectives 113 (2005) 818-822.

9 Robert Kavlock, Gerald T. Ankley, Tim Collette et al. Workshop report: Computational Toxicology: Framework, Partnerships, and Program Development. Reproductive Toxicology 19 (2005) 265-280.

${ }^{10}$ Melvin E. Andersen, Russell S. Thomas, Kevin W. Gaido and Rory B. Conolly. Dose-response modeling in reproductive toxicology in the systems biology era. Reproductive Toxicology 19 (2005) $327-337$. 
Most, however, agreed that a new approach would be relevant for some purposes, but did not appear to be entirely sure how. One pointed out, "There are already great achievements of computational methods in describing, for example, enhanced transport of nanoparticles through membranes, and this cannot be achieved by standard calculations of so-called bulk transport." Another said that "computational models allowed us to describe the electronic structure of carbon nanotubes and the way in which specific molecules and macromolecules interact with them". Those specifically mentioned are listed in Table 8.

Table 8. Stochastic and computational approaches considered relevant.

\begin{tabular}{|l|l|}
\hline Monte Carlo & Monte Carlo simulation; e.g., behaviour of MNMs in the lungs, such as deposition. \\
\hline $\begin{array}{l}\text { High-throughput } \\
\text { screening }\end{array}$ & $\begin{array}{l}\text { Tools for risk assessment must be adaptable, updatable and traceable } \\
\text { providing conditional probabilities for outcomes based on evolving data or } \\
\text { models. High-throughput screening would be very important for industry. }\end{array}$ \\
\hline $\begin{array}{l}\text { Bayesian } \\
\text { methods }\end{array}$ & $\begin{array}{l}\text { Bayesian methods are well suited to obtaining estimates of the value of knowledge to } \\
\text { be obtained by further investigation in a given field. For some compounds (e.g., } \\
\text { titania) so much data has been collected that the use of artificial neural networks } \\
\text { (ANN) could be used for predictions (analogous to the QSAR }\end{array}$ \\
\hline $\begin{array}{l}\text { Stereologedhod) } \\
\text { methods }\end{array}$ & $\begin{array}{l}\text { Stereological methods are suitable; particle trafficking can be quantitatively } \\
\text { estimated and, hence, subsequent (nanotoxic) effects may be explained. }\end{array}$ \\
\hline $\begin{array}{l}\text { Stochastic } \\
\text { methods for PEC }\end{array}$ & $\begin{array}{l}\text { Stochastic methods are suitable for the calculation of predicted environmental } \\
\text { concentration (PEC) values, but there is a need to know production volumes of } \\
\text { these substances and their behaviour during their whole life cycle. One } \\
\text { response to this was: "True, but the industry does not give such data } \\
\text { voluntarily; therefore regulations are needed." }\end{array}$ \\
\hline $\begin{array}{l}\text { Stochastic models } \\
\text { for aerosols }\end{array}$ & $\begin{array}{l}\text { Stochastic models could also be applied for assessing potential effects of } \\
\text { airborne/aerosol MNMs, by comparing them with measurements and known } \\
\text { effects of unintentionally produced air pollutants. }\end{array}$ \\
\hline $\begin{array}{l}\text { Computational } \\
\text { approach to } \\
\text { characterization }\end{array}$ & $\begin{array}{l}\text { Computational models can help us in understanding the mechanical and } \\
\text { chemical properties of MNMs; probabilistic models can help us in } \\
\text { understanding how defects can be organized in the context of MNMs. }\end{array}$ \\
\hline
\end{tabular}

${ }^{\dagger}$ Quantitative structure-activity relationships.

A significant number of experts did not, however, agree with the point about stochastic modelling of aerosols. One said that "we need to investigate more the individual constituents of high hazard", and "indoor/outdoor air require different chemistries" and, furthermore, "it is difficult to monitor particle cloud mobility". Another added that such models could be useful in the future, provided the database of measured effects is sufficient: "Pure modelling based on current knowledge is not sufficient."

\section{Emergence}

The emergence of new properties at ascending/descending scales of complexity (molecular, subcellular, cellular, tissue, organ, etc.) was regarded by some as a probable special concern in the field of nanomaterial toxicology and safety. However, one respondent asserted "no, we are used to dealing with all pharmaceutical responses at the molecular and receptor level" and some others thought it might be but were not sure how. Another thought that emergence is an issue when 
one is dealing with the (gross) health effects of MNMs (consider, for example, cardiopulmonary diseases).

Most agreed that different physical principles may come into play at the nanoscale from those at higher levels of organization, and some thought this had to be significant, but no one could really see what the significance could be, although there are hints that in general it could be one of predictability, uncertainty and therefore manageability and risk assessment. While "we cannot directly transfer our knowledge about the macroworld (one respondent inserted here "or even the molecular world, drugs etc.") to describe the interaction of nano-objects with living entities", it seems that "this is not given enough attention since toxicology tends to be empirical rather than theoretical in approach".

Respondents gave only two examples of emergent properties. Firstly, "Gold nanoclusters of precisely $1.4 \mathrm{~nm}$ intercalate with the major groove of DNA and thus give rise to cytotoxicity, whereas slightly smaller or slightly bigger nanoparticles of gold do not display this effect." Secondly, "nanoparticles of certain sizes may escape from clearance in peripheral lung and cross into the systemic circulation and reach other distal organs while larger particles are trapped in the lung and taken up by macrophages" and cleared by mucociliary activity.

\section{Section 4}

\section{UNCERTAINTY IN NANOMATERIAL TOXICOLOGY}

\section{(Data: absence, quality, comparability, significance, nonlinearity)}

It is clear that the answers in the previous three sections entail a high degree of uncertainty about nanoparticle behaviour under biological conditions at all levels, and therefore toxicity too. One respondent did warn that the nanomaterial toxicology community "should be careful about generalizing MNM behaviour. There is likely an entire spectrum of effects from bioinert to bioreactive to downright toxic". At the other end of the scale of opinion another said that MNMs "are structurally dangerous since they are of the same scale as the basics of living cells. That is why they can mimic, influence and destroy peptidic bio-machines". Presumably, scale itself gives rise to an extremely wide range and complexity of possible biological interferences, with an attendant high degree of uncertainty about what will interfere with what.

The experts were also asked to conceptually characterize this uncertainty about specific behaviours in terms of absence of data, insufficient quantity of data, poor quality of data, practical considerations, or some theoretical or conceptual obstacles. That is, what kind of uncertainty are we dealing with? The answers cover all of these possibilities, but stand in need of detailed elaboration. There is agreement that experimental and observational data are "scarce", and even then it is not always easy to see with any certainty the wider significance of the data that one does have. It was remarked that "comparison of data from different laboratories, materials, techniques, etc. is difficult or impossible at present due to the number of variables and lack of detailed characterization in many cases".

Complexity is compounded by "extraneous" factors. How do we distinguish other effects on humans when measuring exposure hazards, when the test person smokes for example, and is exposed to large amounts of incidental nanoparticles (incinerators, steel factory nearby, car exhaust fumes)? Larger in vivo experiments are needed to find out if data from in vitro experiments can be extrapolated. 
Extracting themes, we now summarize the views of the experts on uncertainty in terms of absence of data, quality of data, parameter control, theoretical issues, linearity/nonlinearity and practical difficulties.

\section{Uncertainty of absence}

Most respondents think that there are enormous gaps in the experimental and observational data needed for the purposes of risk assessment and management, although the data are slowly accumulating. Absence of data ranges from metrological gaps to ignorance of fate in the environment to "nanomaterials production, state of the nanomaterials in these products, usage patterns, etc". In particular, information about the "impacts on living human physiology" of MNMs is "almost totally absent", although there are probably lessons to be learnt from the epidemiology of ultrafine "incidental" particles.

The field of translation of data from in vitro to in vivo to the human presents a "huge gap". As one expert put it: "There is no animal experiment taking six months that will ever give sufficient information to what happens in a human with 20 years of exposure. This is a fact that needs to be communicated, and where possible a sustainable approach to potential risks (cf. the asbestos fibre paradigm) needs to be applied; technical and other measures need to be taken, in order to minimize any emission of such particles, until long-term data are available one day".

Another expert pointed out that there are uncertainty analysis methods, such as Latin hypercube sampling (LHS), which is a statistical method for generating a distribution of plausible collections of parameter values from a multidimensional distribution.

\section{Uncertainty of quality}

A group of toxicologists asserted that the quality of the data is the most important issue in toxicological uncertainty. As one put it, "Have we got the 'right' data-is it meaningful?" Experts think that the main quality-of-data issues cut right across the board, such as the basics of the selection of MNMs for study: characterization, exposure, route, purity, fate, interactivity and time effects. The data are usually fragmentary and often contradictory, and this may or may not be due to a lack of agreement on the methods to be utilized, or on the quality control applied to the dose and response aspects of the experimental design. The research data gained is often of poor quality because of "the lack of specific techniques or because the resulting measurements have undesirably big standard deviations". It is also due to absence of standards (methods, protocols, and positive and negative MNMs). Even scientifically appropriate dose levels for experimentation are not settled, hence the resulting data are of doubtful quality.

The basic scientific requirement of controlling the parameters/variables is often not met in current nanomaterial toxicology. Concerning experiments, "In almost all cases the dose at which an effect is observed is too high to be translated into the predictable setting of exposure for humans." Another said: "I think that 'not enough data' is not the main issue. The experiments on nanoscale systems are difficult and have too many parameters that we lack control over. We simply cannot keep all parameters constant and change only one of them."

One expert explained it this way: "The same nanoparticle will have a different size distribution, mean size, zeta potential, aggregation kinetics, and so on depending on which medium (OECD, cell culture media, etc.) it is dispersed in, and thus 'exposure dose' is 
dependent on the exposure scenario. This has very significant consequences for, among others, cross-comparison across biological species (as each OECD protocol uses a different medium) and cell lines (each of which is optimized using a different medium and range of additives), for in vitro/in vivo correlations as a consequence of the different protein/biomolecule concentrations under the different conditions, and so on". And, concerning cell structure, "the causes of different experimental results will lie in the source of the cells (accurate phenotype); passage number; routine procedures (e.g., trypsinization versus mechanical separation); serum (type/source) and treatment (heat inactivation/nonheat inactivation; commercial media (source); commercial reagents; confluency (dosimetry); cell number/seeding density".

Although absence of adequate data is often the problem, even with a large amount of data there would be the question of establishing significant causal connexions. If results are nonreproducible or too variable then such connexions cannot reliably be made.

\section{Theoretical and conceptual dimensions}

There is the feeling among some respondents that the real basis of uncertainty lies in conceptual or theoretical realms; that is, our basic assumptions about the way things work at the nanoscale may be wrong, narrow or unhelpful. One respondent said, "An experiment is a question posed to nature and if we ask vague questions why should we receive precise answers? The problem is we ask one question, based on which we run one experiment and expect to get one answer.” The suggestion is that we should run many experiments simultaneously to generate new questions and suggest hypotheses.

A number of experts indicated that what may be lacking at present is a model, paradigm or conceptual framework that is suited to nanomaterial toxicology and its ramifications. Three of the more challenging comments on this are:

1) "We need a paradigm to guide our understanding of the data. Hence, the pathogenic paradigm is one such example of a structure-activity relationship that may aid in the understanding of the effects of fibres (it is not the chemical composition of the fibre, but the geometry that dictates the outcome, and the chemistry is only important insofar as this will affect the propensity for biodegradation/biopersistence in a living organism)."

2) "Some of the predictable disorders in humans linked to nanoparticle exposure (e.g., cardiovascular diseases and cancer) develop in a multicausal multistep process. Unless a strong association, like that between asbestos exposure and mesothelioma, is observed a large grey area is unavoidable, independently from the amount of available data."

3) "From a toxicology or environmental exposure perspective, the uncertainties introduced with nanomaterials may only be incremental compared with other materials. However the system-wide effects and uncertainties associated with the trajectory of nanotechnology development may be dominant."

One of the theoretical aspects to receive special attention, following prompting in the questionnaire, is nonlinear behaviour.

\section{Nonlinearity and uncertainty}

One respondent distinguished between computability in a systems approach and nonlinearity: "Linearity is by no means a premiss for a problem to be computable; if something is 
noncomputable, there is lack of knowledge of several variables that have a great influence on the whole outcome; compare with Heisenberg's uncertainty principle or the wave equations for multielectron atoms. Some uncertainty is of a radical nature, having to do with nonlinearitybut it is not yet clear how manageable this is."

Another remark was: "Nonlinearities and deterministic chaos are inherently involved in biological phenomena, but the question is whether these phenomena influence the MNMs' interaction and are expressed strongly in individual experiments. Most chaos experiments were done in physics labs, under strictly controlled conditions, and it is not possible to use the same approach for biological systems. I think that often we are, practically, not able to distinguish stochastic behaviour from deterministic chaos, and only on occasions can we reveal the hidden relationships - and so we are back to the quality of data required for meaningful results."

Another expert pointed out that nonlinearity is recognized in toxicology already, and "there is evidence of nonlinear dose-response behaviour with MNMs, whereby MNMs aggregate at higher concentrations, giving a lower available dose, thus resulting in lower observed effects. Also, it may be useful to consider the cases of mesothelioma (low or infrequent exposure) versus silicosis (high or chronic exposure) as responses to asbestos".

Quite sensibly it was also pointed out that it depends on what exactly is the nature of the nanomaterial toxicology problem one is trying to solve. "It depends on the system but, for example, if biochemical processes in one cell contain a huge number of parallel nonlinear chemical reactions, then dynamical modelling of such a system would inevitably lead to chaotic solutions. This is not a simple question. Perhaps application of fractal theory could lead to a description of some factors affecting the behaviour of MNMs in a concise form of fractal dimension or fractal measure." We may conclude with the observation that quantifying the exact number of entities in the system under study "is sometimes difficult because of nonlinearities in the system and in the measurement techniques. Matter aggregates are often disordered (this is not necessarily synonymous with the unpredictable and inestimable) and the systems used to gather the information are usually linear just in a restricted window".

Other reasons given for the high degree of uncertainty in the field are practical in nature. It is hard to keep up with the fast pace of development of industry in nanotechnology; "human behaviour and commercialization certainly play important roles"; data-sharing is restricted due to competition and commercial confidentiality; physicist and chemists do not cooperate well with medical specialists on the questions of interest; there are practical problems with methods and instruments; and concerning a computational approach, even if there are powerful computational methods, "how far are they being taken up in the nanomaterial toxicology and EHS communities?"

\section{Conclusions}

On the whole, those working in occupational and public health or in human and environmental toxicology have the impression that they do not sufficiently understand the impact of manufactured nanomaterials on living systems. This is perceived as a source of concern. There is a substantial need for long-term documentation and traceability of MNM application and use.

One concluding comment on complexity was: "The enormous variability of MNMs and their characteristics needs to be kept in the context of the enormous genetic variability and 
complexity of biology. Thus, although every individual on the planet is genetically unique, significant trends and patterns exist when viewed in a more coarse-grained approach. It is likely that similar trends and patterns will emerge for MNMs and how they interact with living systems. In the nano-EHS community we may need to reset our approach and adopt those used in other scientific communities to address global issues, such as that of the whole genome project or the proteomics project (HUPO) to collectively address the issues."

The meeting also demonstrated that scientists are creative in proposing strategies to better understand the complexity of the matter. Many expressed the hope that the generation of data for some MNMs may soon allow a distinction between issues where uncertainty is driven by lack of data or by the complexity of the system, which in return would allow the development of appropriate strategies, some of them possibly taking advantage of novel computational techniques.

Taking a broader view, because of the converging global development of technology, the time span between an invention and its large scale global application has diminished. This also happens with the effort to regulate such a new field. There may never have been such a short delay between the very first applications of a technology and a coordinated effort to do the risk assessment (and the exposure tests, methods development, metrology and so on that are prerequisite to risk assessment). "However, it is very important to take one's time to correctly assess, before changing rules or making new ones, because many of the quick findings may soon be refined or discarded."

\section{Acknowledgments}

This work has its basis in the "High-Level Symposium on Nano-Safety Challenges", which took place in Prague, Czech Republic on 29-30 November 2010 under the auspices of the British Embassy Prague, the EU FP7 project NanoImpactNet, the "European Network on the Health and Environmental Impact of Nanomaterials" (grant agreement CSA-CA 218539), the Institute of Experimental Medicine of the Czech Academy of Sciences, the Institute for Work and Health in Lausanne, and the Institute of Occupational Medicine in Edinburgh. The authors are deeply grateful for the support given by these institutions. The authors also extend their thanks to Dr Yasemin J. Erden of the Centre for Bioethics \& Emerging Technologies, St Mary's University College, for assistance in collating the responses. They are appreciative of the contributions from all those who responded, and especially the survey's 3rd stage Expert Panel, namely: Flemming R. Cassee, Otakar Fojt, Ernst Furrer, Peter Gehr, Iseult Lynch and Terry Wilkins. 